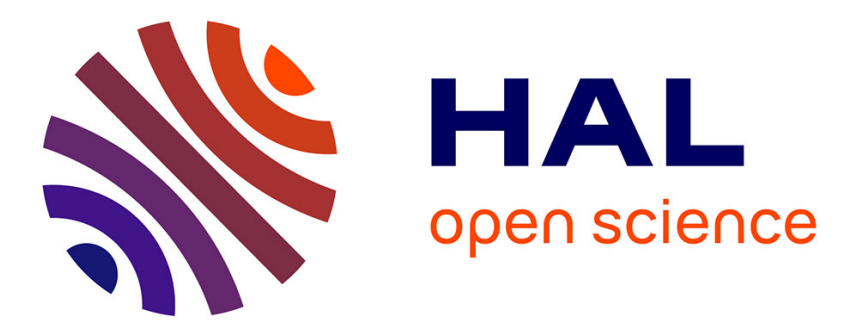

\title{
A Three Steps Methodological Approach to Assess the Engineer-to-Order Operations Environment
}

\author{
Aldo Duchi, Paul Schönsleben
}

\section{To cite this version:}

Aldo Duchi, Paul Schönsleben. A Three Steps Methodological Approach to Assess the Engineer-toOrder Operations Environment. IFIP International Conference on Advances in Production Management Systems (APMS), Sep 2017, Hamburg, Germany. pp.251-258, 10.1007/978-3-319-66926-7_29 . hal-01707256

\section{HAL Id: hal-01707256 \\ https://hal.inria.fr/hal-01707256}

Submitted on 12 Feb 2018

HAL is a multi-disciplinary open access archive for the deposit and dissemination of scientific research documents, whether they are published or not. The documents may come from teaching and research institutions in France or abroad, or from public or private research centers.
L'archive ouverte pluridisciplinaire HAL, est destinée au dépôt et à la diffusion de documents scientifiques de niveau recherche, publiés ou non, émanant des établissements d'enseignement et de recherche français ou étrangers, des laboratoires publics ou privés. 


\title{
A three steps methodological approach to assess the engineer-to-order operations environment
}

\author{
Aldo Duchi and Paul Schönsleben \\ BWI Center for Industrial Management, Department of Management, Technology, and \\ Economics, ETH Zurich, Switzerland \\ \{aduchi, pschoensleben\}@ethz.ch
}

\begin{abstract}
For many companies, “customized” means products that even the most sophisticated of product configuration tools cannot define in advance. Such products need an engineer-to-order operations environment (ETO). This study focuses on the engineering activities of companies adopting an ETO strategy. We observed that these environments are significantly heterogeneous and that this is likely to limit any potential generic applicability of strategies and practices. In this paper, therefore, a three steps methodological approach to support companies in developing a better understanding of their ETO environment is presented: Assessment of product variety and customization, modelling of the ETO process, and measurement of operational performance. Findings from the application of the approach to three industrial partners are then summarized.
\end{abstract}

Keywords: Engineer-to-order, Assessment Approach, Engineering-design

\section{Introduction}

Product-variety management in today's market is, most of the time no longer an orderwinning choice, but an order qualifier [1]. This means that in turbulent market conditions, customers seek out companies that offer shorter delivery times within a customers' price tolerance. In this context, engineer-to-order (ETO) is defined as an operations strategy that is oriented around a high degree of product customization and associated engineering processes for quickly fulfilling customer specifications.

The focus of this study lies in the design and engineering activities of companies adopting an ETO strategy. This encompasses product development processes (PD) usually managed by the Research and Development (R\&D) department - and orderspecific engineering processes (OSE) - usually managed by the Engineering department [2]. These processes have a significant impact on the value chain's downstream material processes, like manufacturing, and therefore significantly impact the company's overall performance.

While working with the three industrial partners of the FastETO research project, in accordance with a literature review, we observed that ETO environments are fundamentally heterogeneous [3]. This is likely to limit any potentially generic applicability of strategies and practices in such a diverse range of ETO environments. Additionally, 
How do the different stakeholders of the value chain view the product? The aim of this question is to align these different standpoints on product structure and data, and emphasizes the importance of defining and managing the relationships between different department's points of view.

Product variants are sometimes designed within a traditional new PD project, but, more likely in an ETO company, have been realized through the specification and delivery of customized products to meet customer requirements. In this way, product variety is generated progressively over several years. When customizing products, the entire product realization process, also referred to the value chain, is affected [4]. Such a process, for instance, can be described based on Suh's domain framework [5]. Within the various departments of a company, therefore, there are several ways of representing product variety and product customization. Indeed, in each phase of the value chain, one or more product structures are used that are pertinent for the overall product description [6]. Therefore, the company needs to conduct an assessment in which all pertinent departments collaborate in creating a general representation of the product variety range. In our approach, we consider it valuable to use three different views, briefly: customer, engineering and production view.

When necessary, the company has to refer to the concept of generic product structure (GPS) and work on a product model representing the product variety range. The GPS models the generic modules of the product and their organization in a part-of hierarchy. Concepts such as parametric, optional and alternative and components are normally encompassed. The problem of selecting parts for a product with high variety can be addressed by the GPS, with the use specialization and generalization semantics. These are typically in the form of type-of relationships between the variants (instances) and the generic modules. Briefly, the GPS aims at describing and modelling product variety without dealing with the product structure of each product variant. For examples of applications of GPS, the reader can refer to the Generic bill of material approach (GBOM)[7]; for an ETO-specific application, please see the Adaptive generic product structure (AGPS)[8]. A useful technique for supporting product modeling is the Product variant master method (PVM)[6].

How do the company's orders differ? The third question aims to raise a company's awareness of the heterogeneity of customer requirements, as of the non-linear consequences of those on the degree of customization and the operations of downstream processes. The goal for the company is to be able to identify, during the sales process phase and depending on the customer requirements, the typology of project/order required. Thanks to this order (or project, product) categorization, the company can then approach customers' requests with differentiated processes (e.g. by advancing engineering knowledge in the pre-award phase) and pay special attention to budgetary and planning activities (e.g. lead-time estimation). Indeed, the company has to be aware of the technical risk and challenges involved when agreeing to satisfy a customer requirement so as not to compromise its profitability.

A basic differentiation the company could make is between "standard product (or order)" and "non-standard product". Alternatively, it could define different classes of order complexity. However, we observed in our companies that even if this variable is usually understood and perceived by the Engineering department, that understanding is 
not valid for the Sales department. It is not always trivial during the offering phase to understand which order requires the development of a new module, the development or specification of a new variant or whether a standard module (or one developed in a previous order) can be re-used. The company should work on the definition of criteria (and, when necessary, of procedures) for identifying the degree of customization and therefore the category of the classification of the product offered.

\section{$2.2 \quad$ ETO process assessment}

The second step of the assessment approach is to map out the as-is process and identify the process activities and resources, particularly focusing on where product information is being processed and where product features and order specifications are produced. In turn, the ETO process model can be analyzed by identifying the most critical problems associated with the process. These provide insight into which problems need to be addressed by the engineering of new and improved processes, and implementation of new technical tools and organizational practices [9].

As-is process mapping. At this stage, the purpose is getting an overview of the as-is process by applying a widespread, easy-to-use and intuitive mapping tool. In this study, the result generated by the various means of data collection and analysis enabled the development of a process map for each of the companies investigated. Process mapping can be carried out using numerous process-mapping formats. The BPMN 2.0 standard is deemed suitable for the task at hand. The format used can include inputs and outputs as well as process parameters and the elements/resources (e.g., IT tools) used in this activity. Also, a characteristic of the ETO process is its cross-department and cross-functional nature. The use of an organizational-oriented process map, to illustrate the relationship between the functional units and the activities for which they are responsible is strongly recommended [10]. Another important characteristic of the ETO process is the variability of the process depending on the product variant of the order. To fulfill specific customer requirements, different levels of customization might be required, and consequently, different activities may or may not be triggered. Based on the results from the first step of the assessment approach, the company should be able to map when and how different activities are launched for the different product/order categories.

Element-activity matrices. Process modeling, as mentioned previously, should not focus exclusively on the activities performed, i.e. on the process side, but also take into account the resources required. Having completed the description of any process mapping and activities, a useful technique is the diagramming of elements/resources to activities in bi-dimensional element-activity matrices. Activities should be listed by type (i.e. PD, specification activities, planning and control activities) and by chronological order, to favor the subsequent qualitative evaluations. Thus, the perspective of element/resource involvement and the requirements of activities are covered with this technique. The diagramming should differentiate between the different types of elements/resources (i.e. departments, tools and technologies, product knowledge, order specifications, customer and suppliers). 


\subsection{ETO operational performance assessment}

The third step of the assessment is to understand which performance requirements are to be put on the process if the company has to meet its overall targets (e.g. profitability, product variety strategy, etc.). This then supports the formulation of the detailed objectives of the improvement project (as for instance the FastETO project).

To provide a framework that enables ETO companies to appropriately measure operational (PD and OSE) process performance, we describe a generic performance measurement system (PMS) for ETO operations called the ETO PMS. Companies, besides using the framework to support the third step of the ETO assessment, can use it to develop and revise their current PMS, used for diagnostic and monitoring purposes. Primarily, the relevant performance dimensions and a guideline for developing firmspecific indicators for performance measurement in all dimensions are presented.

Performance dimensions. The following performance dimensions were adopted: price and cost, further divided in the variable and fixed cost; quality; delivery, both in terms of responsiveness and reliability; flexibility; and learning and innovation. Similar performance dimensions have been postulated for manufacturing operations in literature, such as [11] and [10]. Also, the innovation and learning dimension is directly considered. This is due to its crucial importance to ETO companies that must profit from the knowledge generated during the extension of the product-solution space, a requirement that pertains to most customer orders. These performance dimensions also influence each other, and a resolution of conflicting objectives is necessary most of the time. The relative importance of each of these performance dimensions is of course determined by the strategic motivation to offer ETO products in the first place (e.g. customization as order qualifier, customization as order winner).

KPI Generation Matrix: structure and hierarchy. This matrix entails the classification of all performance indicators according to three different categories. First, each indicator can be allocated to one or several performance dimensions as above outlined. As is clear, companies can measure each performance dimension by combining input, output and process indicators [12]. Second, The ETO process model provides another classification, namely, the element or activity to which a specific indicator belongs. At this stage, the company should have obtained the list of elements and activities as an outcome of the process mapping and description. General indicators are also possible. Third, the PMS is characterized by two hierarchical levels. The higher level, Level 1, contains indicators that aggregate the performance of indicators at the lower level by, for example, providing the average of an indicator across an element type (e.g. a product family). More strategic and general indicators are also attributed to this level. The lower of the two levels, Level 2, details these indicators and breaks them down into components (that describe e.g. a single order performance). More specific, operational and disaggregated indicators are generally associated with level 2. This framework forms the basis for companies to define their own PMS and allows for a greater variety of perspectives than traditionally used. 


\section{$3 \quad$ Findings from the case studies}

This assessment approach has been validated by applying it to three industrial partners of the FastETO research project, manufacturers, respectively, of high-rise elevators, industrial steam turbines, and co-generation plants (refer to [2] for companies' descriptions). The benefits of each of the assessment steps are below summarized.

\subsection{Assessment of product variety and customization}

In summary, it emerges from completion of the first step of the assessment that the first question helps the company to familiarize itself with the objective differences that are present in the ETO environment and consequently in the manufacturing strategies. This also helps the company to familiarize itself with the terminology that can support internal communication, but also in benchmarking with other companies.

The second question helps to diagnose issues in the product variety range, particularly regarding the value created through variety and the understanding of the complexity of product variety. On the one hand, the company can visualize by mean of the product variant master the share of variants that is actually creating value. Indeed, any variant of a product function that does not relate to the customer view does not generate any customer value. On the other hand, the degree of complexity of the product range can be analyzed by observing the relationships between the various views. The higher the number of relations between views, the higher the complexity. Product changes indeed propagate through the value chain to downstream processes, generating tasks and introducing a certain degree of operational performance risk. Therefore, whenever a change is required in the product, the effort generated by the consequent engineering and manufacturing tasks, is proportional to the number of sub-systems that are affected by the change and in turn to the number of relations between views.

The third question highlighted how companies uniformly approached market opportunities and customer orders without considering the heterogeneity of the requirements and therefore the various degrees of customization required. The assessment approach instead raises the companies' awareness of the differences between non-standard and standard solutions, which are already part of the product solution space.

\subsection{ETO process assessment}

Companies' order-specification processes were not always mapped, visible and understood by all stakeholders. However, some process maps were present in all industrial cases: process modeling was not virgin territory. That said, process maps were mostly owned and developed by the quality department to fulfill the requirements for obtaining standard quality certifications. Existing maps and models were not developed within the scope of an improvement project by the other departments.

Product- and order-activity matrices are defined by replacing the generic element type of the element-activity-matrix with the type of product knowledge used as input, and with the type or order specification that is the in- or output of each activity. The 
process visualization enabled by the organization-oriented process map and by the product- and order-activity matrices supported fruitful discussion about cross-department coordination and cooperation issues to be solved [2]. Indeed, the relevance of stakeholder activity on the rest of the value chain, the interdependencies between downstream and upstream activities, as well as the criticality of the strong concurrency of the activities between different departments, were often unclear (e.g. handover from Sales to Engineering once a project has been awarded). Consequently, many improvement ideas arose, from clarifying and formalizing expected input and output to the definition of states and requirement for handover of order specifications. The combined use of the process model and the PMS presented also influenced the definition of new KPIs dedicated to monitoring the delivery performance to internal customers (e.g. technical quality of the specifications).

Attention has also been paid to identifying those activities where useful information and knowledge are generated and whether these are properly acquired and organized. In turn, the analysis focused on those activities where information and knowledge from previous projects are or could be distributed and re-used (e.g. a database of all engineering changes to support standard product-maintenance activities).

IT Tools-Activity matrices supported the investigation of the use of different IT tools and databases in each of the activities. Consequently, the company could often visualize the current fragmentation of product knowledge and order-specification information in several stand-alone databases and, in turn, the time wasted in data collection and transcription tasks, the redundancies of data in various systems, and the potential information discrepancies and specification quality issues.

In a nutshell, the second step of the proposed assessment approach allows companies to detect the above-mentioned criticalities of the current PD and order-specification processes. The PMS, at the third step, allows for generating KPIs to measure and quantify the monetary cost of these criticalities.

\subsection{ETO operational performance assessment}

The KPI generation matrix, including the relevant performance dimensions, were based on the process maps and description obtained with the second step of the assessment approach. They provided structural support during the KPI-generation phase. In turn, these indicators supported the definition of the detailed objectives of the FastETO project at each company. A general finding regarding performance measurement is that the Engineering department was treated as a pure cost center and challenged on cost and efficiency in most cases. As part of the proposed assessment approach, implementation of an extended PMS that considers five performance dimensions enables a more realistic assessment of the benefits of engineering on the overall value chain.

\section{Conclusions}

From a practical perspective, a methodological approach to assess the ETO environment is presented. This innovative approach is a combination of and adaptation to the 
ETO environment of existing managerial techniques. In contrast to traditional methodological approaches, we emphasize the need to sequentially incorporate in three steps, the assessment of the peculiarities of the ETO product, together with the modeling of the processes, and the measure of the operational performance over five identified dimensions. The three steps of the assessment are all needed and in that specific order. Indeed, with the first step, it is possible to cluster orders into "standard" and "nonstandard" categories. These imply different processes that can then be captured in the process-modeling step. Identified process activities and process elements are consequently used, during the third step, in the KPI generation matrix.

The approach supports managers of ETO companies in reaching greater transparency and a clearer overview, and thus a better understanding of their operational environment. The assessment approach has been validated through its application to three companies, differing in size, volume, maturity and product characteristics, and has been shown to be a fundamental step in the early phase of the FastETO improvement project in assessing and analyzing the initial situation of the enterprise before formulating objectives and searching for potential solutions.

\section{References}

1. Hendry LC (2010) Product customisation: an empirical study of competitive advantage and repeat business. Int J Prod Res 48:3845-3865.

2. Schönsleben, P, Weber, S, Koenigs, S, Duchi, A (2017) Different types of cooperation between the R\&D and Engineering departments in companies with a design-to-order production environment. CIRP Ann - Manuf Technol

3. Willner O, Powell D, Gerschberger M, Schönsleben P (2016) Exploring the archetypes of engineer-to-order: an empirical analysis. Int J Oper Prod Manag 36:242-264.

4. Jiao J, Zhang L, Pokharel S (2007) Process platform planning for variety coordination from design to production in mass customization manufacturing. IEEE Trans Eng Manag 54:112129.

5. Suh NP (1998) Axiomatic design theory for systems. Res Eng Des - Theory, Appl Concurr Eng 10:189-209.

6. Hvam L, Mortensen NH, Riis J (2008) Product customization. Springer Science \& Business Media

7. Hegge HMH, Wortmann JC (1991) Generic bill-of-material: a new product model. Int J Prod Econ 23:117-128.

8. Brière-Côté A, Rivest L, Desrochers A (2010) Adaptive generic product structure modelling for design reuse in engineer-to-order products. Comput Ind 61:53-65.

9. Schönsleben P (2012) Methods and tools that support a fast and efficient design-to-order process for parameterized product families. CIRP Ann - Manuf Technol 61:179-182.

10. Schönsleben P (2016) Integral logistics management: Operations and supply chain management within and across companies. CRC Press

11. Neely A, Gregory M, Platts K (2005) Performance measurement system design. Int J Oper Prod Manag 15:80-116.

12. Chiesa V, Frattini F, Lazzarotti V, Manzini R (2009) Performance measurement in R\&D: Exploring the interplay between measurement objectives, dimensions of performance and contextual factors. R D Manag 39:488-519. 